\title{
PORTA-ENXERTOS UTILIZADOS NA CITRICULTURA
}

\author{
CITRICULTURE ROOTSTOCKS IN USE
}

\author{
Gilmar Schäfer $^{1}$ Marinês Bastianel ${ }^{2}$ Ana Lúcia Cunha Dornelles ${ }^{3}$
}

\section{- REVISÃO BIBLIOGRÁFICA -}

\section{RESUMO}

A muda cítrica é o insumo mais importante na formação de um pomar. As características mais importantes da muda cítrica são a origem do enxerto e do porta-enxerto, a qualidade do sistema radicular e a sua sanidade. Os portaenxertos são capazes de influenciar várias características horticulturais e sanitárias nas árvores e nos frutos cítricos, como: sólidos solúveis totais, tamanho da copa e do fruto, resistência a moléstias e ao frio, distribuição da raízes, etc. O principal portaenxerto utilizado no Brasil (cerca de 80\%) é o limoeiro 'Cravo' (Citrus limonia Osbeck cv. Cravo). No Rio Grande do Sul, mais especificamente, destaca-se o Poncirus trifoliata (L.) Raf em mais de $90 \%$ dos pomares. Isso torna a citricultura vulnerável ao surgimento de moléstias que afetem estes porta-enxertos, como ocorreu na década de 40 em todo o Brasil com a 'Tristeza' dos citros em plantas enxertadas sobre laranjeira azeda, e, mais recentemente, com o 'declínio'. Assim, o conhecimento das características dos diversos porta-enxertos e de algumas particularidades do uso destes é de grande importância para a diversificação e escolha do porta-enxerto a ser utilizado pelo citricultor.

Palavras chave: Citrus sp., qualidade do fruto, desenvolvimento vegetativo, incompatibilidade.

\section{SUMMARY}

Citric scion is the most important factor in orchard formation. The citric scion most important characteristics are the graft and rootstock origin, the root system quality and health. The rootstock affects several horticultural and sanitary characteristic in the citric trees and fruits, as total soluble solids, canopy and fruit size, diseases and cold resistance, roots distribution, etc.
Rangpur lime (Citrus limonia Osbeck cv. 'Cravo') is the most used rootstock in Brazil (about 80\%), however in the State of Rio Grande do Sul, Brazil, Trifoliate orange (Poncirus trifoliata [L.] Raf.) is found in more than $90 \%$ of the orchards. This makes citriculture vulnerable to rootstock diseases appearance, as it happened in the 40's in the whole country, when citrus 'Tristeza' virus, killed almost all plants grafted on Sour Orange, and more recently, the problem is with the citrus 'decline'. So the knowledge of the several rootstock characteristics and some of their use particularities can help the citrus growers in the decision process.

Key words: Citrus sp., fruit quality, vegetative growth, incompatibility

\section{INTRODUÇÃO}

O Brasil é o maior produtor mundial de frutas cítricas, com uma produção que, segundo a FAO (1998), ultrapassa 23 milhões de toneladas. Deste montante, a produção principal é de laranjas, sendo que o país ocupa, atualmente, a primeira posição em produção e exportação de suco de laranja concentrado e congelado. As tangerineiras também ocupam destaque na produção mundial (quarto lugar - FAO, 1996), principalmente as cultivares 'Poncã' e 'Murcote'. No Brasil, estima-se que são cultivados mais de 2,2 milhões de hectares com cítricos, envolvendo mais de 400 mil empregos diretos, 20 mil

\footnotetext{
${ }^{1}$ Engenheiro Agrônomo, aluno do Programa de Pós-graduação em Fitotecnia, Faculdade de Agronomia, Universidade Federal do Rio Grande do Sul (UFRGS). E-mail: schafer@ vortex.ufrgs.br. Autor para correspondência

${ }^{2}$ Engenheiro Agrônomo, M.Sc., Departamento de Horticultura e Silvicultura, UFRGS. E-mail: bastiane@vortex.ufrgs.br.

${ }^{3}$ Engenheiro Agrônomo, Doutor, professor Adjunto, Faculdade de Agronomia, Departamento de Horticultura e Silvicultura, UFRGS, Av. Bento Gonçalves 7712, CP 776,91501-970. E-mail: alcunha@ vortex.ufrgs.br.
} 
citricultores e 17 indústrias de suco (MORAES $\boldsymbol{e t}$ al., 1998).

A citricultura, apesar de inúmeras dificuldades, vem apresentando incremento considerável na área plantada, e suas perspectivas futuras são promissoras, principalmente, pela diversificação de mercados consumidores. O país possui condições edafoclimáticas favoráveis à citricultura, embora a maior produção verificada nos últimos anos tenha sido causada unicamente pelo aumento da área plantada. A produtividade é muito baixa, em comparação com a de outros países (RAMOS et al., 1997).

O Rio Grande do Sul apresenta um grande potencial para produção de citros para o consumo in natura, por apresentar condições climáticas favoráveis para o desenvolvimento do fruto com características físico-químicas adequadas para o consumo fresco. Em termos econômicos, a produção de frutos para consumo in natura é de grande importância, principalmente na Depressão Central do Estado, onde sua produção está localizada nas margens dos rios Caí e Taquari, cuja região é composta, em grande parte, por pequenas propriedades rurais (DORNELLES, 1991). Embora a citricultura gaúcha mereça destaque no mercado de frutas frescas, a sua produção ainda não é suficiente para abastecer o mercado interno. Segundo JOÃO (1998), estima-se que $50 \%$ dos citros comercializados no estado têm sido importado de outros estados, do Uruguai e até da Espanha.

A muda cítrica é o insumo mais importante na formação de um pomar. $\mathrm{O}$ caráter perene da cultura de citros coloca fundamental importância na escolha da muda, que é plantada e cuidada por 6 a 8 anos antes de revelar seu máximo potencial na produtividade e qualidade do fruto. Outros aspectos, como a longevidade do pomar, só serão reconhecidos em um intervalo ainda maior após o plantio. As características mais importantes da muda cítrica são a origem do enxerto e do porta-enxerto (plantas matrizes) e a qualidade do sistema radicular (LIMA, 1986).

Os porta-enxertos de plantas cítricas afetam mais de 20 características hortícolas e patológicas da cultivar copa e seus frutos, sendo seu uso considerado essencial na citricultura (CASTLE $\boldsymbol{e t}$ al., 1992). No Rio Grande do Sul, existem atualmente 216 produtores de mudas cítricas registrados no Ministério da Agricultura, estimando-se de 2 a 2,5 milhões de mudas produzidas no último ano (JOÃO, 1999). Segundo MORAES et al. (1998), a maioria dos viveiristas registrados produzem mudas de bom aspecto, vigorosas que obedecem aos padrões legais visuais para comercialização. Porém, com certa freqüência, as mudas deixam a desejar quanto à origem genética (mistura de variedades copa e porta-enxertos) e à contaminação por viroses (exocorte, sorose e xiloporose), fatores que criam sérios problemas ao citricultor, pois os pomares formados com estas mudas têm o rendimento e a longevidade comprometidos, além de influenciar na comercialização e na época de colheita.

Outro problema da produção de mudas no nosso Estado é a falta de diversificação de portaenxertos. Estima-se que mais de $90 \%$ das mudas são enxertadas sobre Poncirus trifoliata, o que torna a citricultura vulnerável ao surgimento de moléstias que afetem este porta-enxerto, como ocorreu na década de 40, no Estado de São Paulo ('Tristeza' dos citros em plantas enxertadas sobre laranja 'Azeda'), e mais recentemente com o 'declínio' (MORAES et al., 1998).

O objetivo desta revisão bibliográfica foi a de caracterizar os porta-enxertos mais utilizados na citricultura, bem como abordar aspectos teóricos da sua influência na cultivar copa.

\section{IMPORTÂNCIA DO PORTA-ENXERTO}

A frase - "a escolha e o uso de um portaenxerto podem significar a diferença entre o sucesso e o fracasso de um pomar" - proferida pelo autor americano do Estado da Flórida, Jasper Joiner, em 1955, além de bastante oportuna na época, ainda é importante nos dias atuais. A necessidade de superar novas dificuldades e alcançar objetivos pertinentes à modernização da citricultura mundial vem priorizando esta importante arma da horticultura: os portaenxertos (Castle et al. apud CARLOS et al., 1997).

Capazes de influenciar várias características horticulturais e fitopatológicas nas árvores e nos frutos cítricos, os porta-enxertos podem refletir a aptidão do pomar em relação ao destino da produção, em função da qualidade da mesma. Tanto a qualidade dos frutos quanto a produtividade do pomar são enormemente influenciadas pelas condições de clima, pelos fatores relacionados à adubação e ao solo, pelo espaçamento, pelo manejo e por vários outros fatores. Entretanto, sob as mesmas condições, alguns porta-enxertos se destacam pela excelência em determinados aspectos. Nossa citricultura, essencialmente voltada à demanda internacional de suco, vem se deparando com mercados mais exigentes. A escolha de um porta-enxerto adequado pode propiciar frutos de melhor qualidade, que atendam às exigências internacionais para exportação de frutas frescas, pode propiciar frutos de tamanho maior ou em épocas de melhor preço no mercado interno e, finalmente, pode ainda colaborar com as indústrias processadoras na produção de frutos com maiores 
teores de suco e sólidos solúveis totais (CARLOS $\boldsymbol{e t}$ al., 1997, DI GIORGI, et al., 1993).

$\mathrm{O}$ porta-enxerto induz alterações à variedade copa no seu crescimento, tamanho, precocidade de produção, produtividade, época de maturação e peso dos frutos, coloração da casca e dos frutos, teor de açúcares e de ácidos, permanência dos frutos na planta, conservação após a colheita, transpiração das folhas, fertilidade do pólen, composição química das folhas, capacidade de absorção, síntese e utilização de nutrientes, tolerância a salinidade, resistência à seca e ao frio, resistência e tolerância a moléstias e pragas e resposta a produtos de abscisão (POMPEU JÚNIOR, 1991).

\section{Influência do porta-enxerto sobre as característi- cas relacionadas ao fruto e/ou à produção}

A qualidade dos frutos cítricos é intrínseca à variedade, sendo no entanto, influenciada por inúmeros fatores: o clima, o solo, a adubação, os tratos culturais, os tratamentos fitossanitários e o porta-enxerto. Existe no entanto um grande número de fatores de qualidade influenciados pelo portaenxerto, a saber: tamanho e peso dos frutos, cor e espessura da casca, conteúdo de suco, sólidos solúveis totais (brix) e acidez, cor do suco, conteúdo em óleo da casca, amargor, conteúdo em sais minerais, granulação, teor de ácidos graxos e conservação póscolheita (STUCHI $\boldsymbol{e}$ t al., 1996 e FIGUEIREDO \& HIROCE, 1990).

Entretanto a magnitude da influência do porta-enxerto é maior no que se refere à produção de frutos. Neste item, em pomeleiro testado por WUTSCHER (1988), sobre 45 porta-enxertos, foram registrados acréscimos de até $230 \%$, enquanto para circunferência do fruto, espessura da casca, conteúdo de suco e ratio as variações foram de 22, 37, 17 e $28 \%$ respectivamente. Além destes, o autor relatou que os diferentes porta-enxertos afetaram as características dos frutos, tais como: conteúdo de vitamina $\mathrm{C}$, índices de óleo na casca e composição mineral de todas as partes da planta.

Vários ensaios foram ou vêm sendo conduzidos, com o objetivo de testar diferentes composições de cultivares copa/porta-enxertos às diferentes condições edafo-climáticas existentes. Alguns desses serão descritos a seguir, com o objetivo de exemplificar a diversidade de resultados existentes e propor os melhores porta-enxertos a algumas cultivares copa.

Em um ensaio de competição de dez porta-enxertos para a laranjeira 'Barão', no Instituto Agronômico de Campinas (SP), durante os anos de 1969-80, realizado por FIGUEIREDO et al. (1981) foram encontradas diferenças de produtividade de $400 \%$ entre os extremos (Tangelo 'Orlando' - Limoeiro Rugoso Nacional).

A performance do limoeiro 'Siciliano' foi testada em 16 porta-enxertos, no município de Taquari, Estado do Rio Grande do Sul, durante os anos de 1976 a 84. Os autores observaram que os citranges C-8, C-13, C-14, C-20, desenvolvidos a partir de cruzamentos realizados na Estação Experimental de Taquari, parecem ser boas alternativas como uso para porta-enxertos nesta cultivar, sendo o C-13 o mais promissor. Também o 'Volkameriana' (Citrus volkameriana) obteve uma boa performance (PORTO, 1992). Já o tangoreiro 'Murcote', testado sobre 12 porta-enxertos, também em Taquari, durante os anos de 1977 a 1986, não obteve os mesmos resultados com os citranges citados acima, induzindo baixas produções, não sendo recomendados como porta-enxertos para esta cultivar (Tabela 1). Os porta-enxertos que induziram maior produtividade foram os limoeiros 'Rugoso da Flórida' e 'Cravo Taquari’ (SOUZA et al., 1992).

Em São Paulo, para a 'Mexeriqueiras-doRio' (Citrus deliciosa Tenore), estudou-se o comportamento de dez porta-enxertos sobre a produção. Após sete anos de colheita, as maiores produções relacionaram-se, em ordem decrescente, aos porta-enxertos tangerineira 'Sunki', laranjeira 'Flórida Sweet', limoeiro 'Cravo' e tangerineira Cleópatra. Os citranges 'Troyer', 'Carrizo' e 'Morton' e o Poncirus trifoliata apresentaram as mais baixas produções (FIGUEIREDO et al., 1979).

Também, em São Paulo, avaliou-se o comportamento da laranjeira 'Valência' sobre 12 porta-enxertos. Após quatro colheitas, entre o quinto e o oitavo ano, o porta-enxerto Poncirus trifoliata conferiu uma produção média baixa, com $30,37 \mathrm{~kg}$ por planta, quando comparado aos limoeiros 'Cravo' e 'Volkameriano', que proporcionaram produções de 154,81 e $150,12 \mathrm{~kg}$ por planta, respectivamente (ALVARENGA $\boldsymbol{e t}$ al., 1986). O comportamento da laranjeira 'Valência' sobre oito porta-enxertos, também foi avaliado por ROBERTO et al. (1999). Nas três primeiras safras, os autores observaram que os limoeiros 'Cravo' e 'Volkameriano' apresentaram as maiores médias de produção de frutos por área e planta $(38,67$ e $35,8 \mathrm{t} / \mathrm{ha}$ e 96,77 e $89,49 \mathrm{~kg} /$ planta respectivamente). Os citrangeiros 'Troyer' e 'Carrizo' e tangeleiro 'Orlando' apresentaram as menores médias de produtividade inicial.

Em um experimento com laranjeiras 'Pêra', clone Bianchi, enxertadas sobre 11 portaenxertos, em Cordeirópolis-SP, relacionou-se a produtividade de 20 anos e as características físicas dos frutos, chegando a diferenças médias de produção de 
Tabela 1 - Efeito de porta-enxertos cítricos na produtividade e qualidade de laranjeiras (Citrus sinensis).

\begin{tabular}{|c|c|c|c|c|c|c|c|}
\hline $\begin{array}{l}\text { Cultivar copa/porta- } \\
\text { enxerto }\end{array}$ & $\begin{array}{l}\text { Produtividade } \\
\text { (Kg/árvore) }\end{array}$ & $\begin{array}{l}\text { Peso médio } \\
\text { do fruto }(\mathrm{g})\end{array}$ & $\begin{array}{c}\text { Espessura } \\
\text { da casca } \\
(\mathrm{mm})\end{array}$ & $\begin{array}{c}\text { Conteúdo } \\
\text { de suco } \\
(\%)\end{array}$ & $\begin{array}{c}\text { Sólidos } \\
\text { Solúveis } \\
(\%)\end{array}$ & $\begin{array}{l}\text { Acidez } \\
(\%)\end{array}$ & Ratio \\
\hline
\end{tabular}

'Valência'a

Citrange 'Carrizo'

Mandarina 'Cleópatra'

Limoeiro 'Rugoso'

Laranjeira azeda

Citrumeleiro 'Swingle'

Trifoliata

Diferença $(\%)^{\mathrm{e}}$

'Valência'b

Citrange 'Carrizo'

Mandarina 'Cleópatra'

Limoeiro 'Rugoso'

Laranjeira azeda

Citrumeleiro 'Swingle'

Trifoliata

$\mathrm{P}$,-enxertos Estaquia

Diferença (\%)

'Hamlin'c

Citrange 'Troyer'

Tangerineira 'Sunki'

Limoeiro 'Rugoso'

Laranjeira azeda

Citrumeleiro 'Swingle'

Trifoliata

Diferença (\%)

'Murcote'd

C 20

C 32

C 65

'Volkameriana'

'Rugoso Nacional'

'Rugoso da Flórida'

'Rugoso da África'

'Caipira'

'Cravo Taquari'

Citrange 'Troyer'

Tang. 'Cleópatra

C 14

\begin{tabular}{|c|c|c|c|c|c|c|}
\hline 229 & 195 & - & 56,5 & 11,6 & 1,00 & 11,6 \\
\hline 168 & 210 & - & 58,3 & 11,2 & 0,99 & 11,4 \\
\hline 254 & 205 & - & 54,5 & 10,8 & 0,96 & 11,2 \\
\hline 188 & 211 & - & 58,6 & 11,7 & 1,06 & 11,0 \\
\hline 131 & 201 & - & 57,4 & 11,6 & 1,00 & 11,6 \\
\hline 139 & 213 & - & 55,4 & 12,0 & 0,99 & 12,2 \\
\hline 94 & 9 & - & 8 & 11 & 10 & 11 \\
\hline 188 & 206 & - & 59,0 & 11,7 & 0,71 & 16,6 \\
\hline 176 & 180 & - & 60,0 & 11,4 & 0,70 & 16,3 \\
\hline 233 & 221 & - & 54,1 & 10,6 & 0,68 & 15,5 \\
\hline 155 & 196 & - & 59,7 & 11,5 & 0,73 & 15,8 \\
\hline 147 & 191 & - & 58,1 & 11,3 & 0,67 & 16,9 \\
\hline 127 & 198 & - & 58,0 & 11,6 & 0,68 & 17,1 \\
\hline 108 & 212 & - & 59,4 & 10,6 & 0,66 & 16,2 \\
\hline 216 & 23 & - & 11 & 10 & 11 & 10 \\
\hline 120 & 187 & 3,8 & $43^{c}$ & 10,2 & 0,66 & 15,5 \\
\hline 77 & 191 & 4,0 & 43 & 10,1 & 0,66 & 15,3 \\
\hline 90 & 187 & 4,1 & 38 & 8,5 & 0,66 & 12,9 \\
\hline 125 & 206 & 4,6 & 42 & 10,3 & 0,71 & 14,5 \\
\hline 150 & 171 & 3,7 & 44 & 10,3 & 0,74 & 13,9 \\
\hline 116 & 176 & 3,7 & 44 & 9,9 & 0,63 & 15,7 \\
\hline 95 & 20 & 24 & 16 & 21 & 17 & 22 \\
\hline
\end{tabular}

Diferença (\%)

\section{$23,4^{\mathrm{e}}$}

15,4

27,6

41,1

27,0

54,6

39,8

38,7

57,2

26,9

40,6

morto

271,43

Fonte: Adaptado de CASTLE (1995).

${ }^{a}$ Dados de árvores maduras, com solo profundo, arenoso e com irrigação. Média de 9 anos;

${ }^{\mathbf{b}}$ Dados de árvores maduras, crescendo em ambiente variável, em solo mal drenado e com irrigação.

Média de 9 anos;

${ }^{\mathbf{c}}$ Dados de rendimento médio de 8 anos: Dados de qualidade do suco são de 4 anos e meio. Os dados de conteúdo de suco são baixos em comparação aos demais, pelo fato da extração ser diferenciada;

${ }^{d}$ Fonte: SOUZA et al. (1992). Média de 10 anos ( $\mathrm{kg}$ de frutos/planta).

${ }^{\mathrm{e}}$ Diferenças entre os valores altos e baixos dentro de cada cultivar.

até $159 \%$ entre o Limoeiro 'Rugoso da Flórida e Trifoliata 'Limeira'. Os porta-enxertos limoeiros
'Rugoso da Flórida' e 'Rugoso da África', tangeleiros 'Orlando' e tangerineira 'Sunki' foram considerados como boas alternativas para a laranjeira 'Pêra' Bianchi. O efeito dos porta-enxertos sobre a qualidade dos frutos não é limitante ao uso destes (TEÓFILO SOBRINHO et al., 1999).

Quanto a qualidade do fruto, não é claro como o portaenxerto exerce sua influência. Alguns dos efeitos parecem estar relacionados com tamanho (frutos grandes tem menor teor de SST) ou com efeitos nutricionais (o potássio aumenta $\mathrm{o}$ tamanho do fruto e a acidez). Os efeitos do porta-enxerto podem variar de ano para ano, de área para área e com práticas culturais, ou seja, pela interação do genótipo com o ambiente em si (WUTCHER, 1988).

Os portaenxertos tem efeito significativo no desenvolvimento do fruto e a maior parte dessa influência é devida a capacidade de fornecer água para a planta e, em segundo lugar, a absorção de nutrientes (ALBRIGO, 1992; CASTLE, 1995). Porta-enxertos mais vigorosos são melhores extratores de umidade do solo e mantêm a planta sob menor estresse hídrico. Essa é a maior razão pela qual muitos porta-enxertos induzem baixa concentração de sólidos solúveis nos frutos, mas produzem mais sólidos solúveis por 
planta (STUCHI, 1996). CASTLE (1995) cita que em um experimento com laranjeiras 'Hamlim' em vários porta-enxertos encontrou-se diferenças grandes de sólidos solúveis (Tabela 1), concluindo que esta referia-se ao fato de as folhas das árvores suprirem carboidratos ao fruto, entretanto, o portaenxerto determina uma maior ou menor quantidade de folhas.

Frutos grandes, com casca grossa e rugosa, baixas concentrações de sólidos solúveis e ácidos no suco, estão associados às plantas enxertadas em porta-enxertos de crescimento rápido e vigoroso, estando incluídos nesta categoria os seguintes: limoeiro 'Rugoso', Palestine Sweet lime, Citrus macrophylla, Citrus pennivesiculata, limoeiro 'Cravo' e cidra. Já as variedades enxertadas sobre porta-enxertos pouco vigorosos tem menor desenvolvimento vegetativo e tendência para produção de frutos menores, com casca mais lisa e alto conteúdo de sólidos e ácidos no suco. Neste segundo grupo enquadram-se o Poncirus trifoliata e alguns de seus híbridos, como citranges e citrumelos. Variedades enxertadas em laranjeira caipira ou laranjeira azeda produzem frutos com características intermediárias (Reitz \& Embleton apud STUCHI et al., 1996).

A tabela 1 demonstra a influência dos porta-enxertos na qualidade da fruta cítrica. CASTLE, (1995) descreve diferenças de produtividade (94 a 216\%) e qualidades físico químicas dos frutos. Como exemplo, o autor descreve as diferenças, na qualidade dos frutos, existentes entre plantas enxertadas sobre laranjeira azeda (Citrus aurantium L.) e limoeiro 'Rugoso' (Citrus jambhiri lush.). Plantas enxertadas sobre laranjeira azeda produzem frutos de qualidade superior, por causa da alta concentração de sólidos solúveis, bom sabor e tamanho de fruta, e casca relativamente fina. Em contrapartida frutas de plantas enxertadas sobre limoeiro ' $\mathrm{Ru}$ goso' são grandes, com baixos conteúdos de sólidos solúveis e acidez, de casca mais espessa, e não conserva tanto o fruto no pé quando comparado aos outros porta-enxertos.

Influência dos porta-enxertos sobre as características de crescimento da planta

Os porta-enxertos afetam diretamente o vigor da variedade copa enxertada, estando relacionado diretamente ao genótipo e suas relações. Com isto os porta-enxertos induzem diferenças marcantes no tamanho da copa e de sua produção.

A bibliografia não esclarece suficientemente os parâmetros relacionados ao crescimento da planta. Entretanto, os porta-enxertos tem diferenças significativas no desenvolvimento do sistema radicular, determinando a maior ou menor quantidade de radicelas no sistema radicular da planta e, também, a distribuição delas no solo (MOREIRA, 1992). Segundo VITTI (1992), a capacidade de um portaenxerto vigoroso absorver mais água e colocar a raiz em contato com os nutrientes propiciaria uma maior absorção destes, quer por interceptação radicular, fluxo de massa ou difusão, elevando os níveis nutricionais da planta e com isso aumentando seu crescimento.

Diferentes experimentos foram conduzidos, com o objetivo de comparar o desenvolvimento vegetativo de cultivares copa em vários porta-enxertos. Em geral o porta-enxerto Poncirus trifoliata e alguns dos seus híbridos induzem um menor vigor a cultivar copa, quando comparados com porta-enxertos mais vigorosos como o limoeiro 'Cravo'(Tabela 2). Com laranjeira 'Valência' foi relatado diferenças de $44 \%$ de crescimento, entre quatro porta-enxertos, em volume da copa $\left(\mathrm{m}^{3}\right)$ (LEDO et al., 1999). Para a tangerineira 'Ponkan' verificou-se, que o desenvolvimento vegetativo, durante dez anos de cultivo, foi menor para o Poncirus trifoliata, quando comparados aos porta-enxertos 'Ponkan' e 'Fuju' (ZHUANG et al., 1993).

Quanto a composição foliar de nutrientes na parte aérea, observa-se que o porta-enxerto Poncirus trifoliata, em geral é que apresenta os maiores níveis, principalmente de $\mathrm{N}, \mathrm{K}$ e $\mathrm{Mn}$ (ZHUANG et al., 1993; HIROCE et al., 1981; VANNIERE \& MARCHAL, 1992),

\section{Influência dos porta-enxertos sobre a tolerância} ou suscetibilidade à doenças

Os porta-enxertos possuem diferentes graus de tolerância ou suscetibilidade à algumas doenças. Serão abordadas algumas doenças como gomose, tristeza dos citros e declínio, e na tabela 2, encontra-se um resumo dos principais porta-enxertos e suas características quanto a essas doenças.

\section{Gomose}

As doenças causadas pelos fungos do gênero Phytophthora sp. constituem-se em sério problema desde a sementeira até a fase de pós-colheita. As ocorrências em pomares comerciais, normalmente são as que chamam maior atenção dos produtores em função dos prejuízos envolvidos.

Por apresentarem uma situação geográfica intimamente relacionada ao volume de solo abrangi- 
Tabela 2 - Características dos porta-enxertos cítricos em relação à doenças, comportamento quanto a copa e condições ambientais

\begin{tabular}{|c|c|c|c|c|c|c|c|c|c|c|c|c|}
\hline \multirow[b]{2}{*}{$\begin{array}{c}\text { Característica } \\
\text { avaliada }\end{array}$} & \multicolumn{12}{|c|}{ Porta-enxerto } \\
\hline & $\begin{array}{l}\text { Laranj } \\
\text { Doce }\end{array}$ & $\begin{array}{c}\text { Tanger. } \\
\text { Cleópa- } \\
\text { tra }\end{array}$ & $\begin{array}{l}\text { Limoeiro } \\
\text { Cravo }\end{array}$ & $\begin{array}{c}\text { Limoeiro } \\
\text { Volka- } \\
\text { meriano }\end{array}$ & $\begin{array}{l}\text { Limoeiro } \\
\text { Rugoso }\end{array}$ & Trifoliata & $\begin{array}{c}\text { Citrume- } \\
\text { lo } \\
\text { Swingle }\end{array}$ & $\begin{array}{l}\text { Citrange } \\
\text { Troyer }\end{array}$ & $\begin{array}{l}\text { Citrange } \\
\text { Carrizo }\end{array}$ & $\begin{array}{l}\text { Tangelo } \\
\text { Orlando }\end{array}$ & $\begin{array}{l}\text { Tanger. } \\
\text { Sunki }\end{array}$ & $\begin{array}{r}\text { Laranj. } \\
\text { azeda }\end{array}$ \\
\hline Gomose & I & $S$ & I & I & I & $S$ & $\mathrm{~S}$ & A & $\mathrm{A}$ & A & I & S \\
\hline Tristeza & S & $\mathrm{S}$ & S & S & S & S & $\mathrm{S}$ & $\mathrm{S}$ & $\mathrm{S}$ & $\mathrm{S}$ & S & I \\
\hline Exocorte & S & S & I & S & S & I & I & I & I & $\mathrm{S}$ & S & S \\
\hline Sorose & I & S & A & S & S & I & DI & A & $\mathrm{A}$ & S & S & S \\
\hline Xiloporose & $S$ & DI & I & S & S & $\mathrm{S}$ & $\mathrm{S}$ & A & A & I & S & $\mathrm{S}$ \\
\hline Declínio & S & $\mathrm{S}$ & I & I & I & I & $\mathrm{S}$ & I & I & $\mathrm{S}$ & S & S \\
\hline Drenagem & I & I & I & A & I & $\mathrm{S}$ & DI & I & I & S & I & S \\
\hline Seca & I & A & $\mathrm{S}$ & $\mathrm{S}$ & S & I & $\mathrm{S}$ & A & $\mathrm{S}$ & I & A & $\mathrm{S}$ \\
\hline \& Arenoso & I & I & $\mathrm{S}$ & S & S & I & $\mathrm{S}$ & I & I & I & I & S \\
\hline 융 Misto & I & I & $\mathrm{S}$ & $\mathrm{S}$ & S & I & $\mathrm{S}$ & I & I & I & A & $\mathrm{S}$ \\
\hline 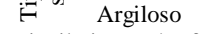 & $\mathrm{S}$ & $\mathrm{S}$ & $\mathrm{S}$ & $\mathrm{S}$ & I & $\mathrm{S}$ & I & $\mathrm{S}$ & $\mathrm{S}$ & $\mathrm{S}$ & I & $\mathrm{S}$ \\
\hline Distribuição raízes ${ }^{\mathbf{a}}$ & M & M & $\mathrm{P}$ & $\mathrm{P}$ & $\mathrm{P}$ & $\mathrm{R}$ & $\mathrm{P}$ & M & M & DI & DI & M \\
\hline Qualidade do fruto & $\mathrm{S}$ & $\mathrm{S}$ & $\mathrm{S}$ & $\mathrm{S}$ & I & $\mathrm{S}$ & A & A & A & A & $\mathrm{S}$ & $\mathrm{S}$ \\
\hline Vigor & $\mathrm{S}$ & A & $\mathrm{S}$ & $\mathrm{S}$ & $\mathrm{S}$ & I & $\mathrm{S}$ & $\mathrm{S}$ & $\mathrm{S}$ & $\mathrm{S}$ & A & $\mathrm{S}$ \\
\hline Tamanho da copa & $\mathrm{S}$ & $\mathrm{S}$ & $\mathrm{S}$ & $\mathrm{S}$ & $\mathrm{S}$ & $\mathrm{S}$ & $\mathrm{S}$ & $\mathrm{S}$ & $\mathrm{S}$ & $\mathrm{S}$ & $\mathrm{S}$ & $\mathrm{S}$ \\
\hline Resistência ao frio & $\mathrm{S}$ & $\mathrm{S}$ & $\mathrm{S}$ & $\mathrm{S}$ & I & $\mathrm{S}$ & $\mathrm{S}$ & $\mathrm{S}$ & $\mathrm{S}$ & $\mathrm{S}$ & A & $\mathrm{S}$ \\
\hline Longevidade & $\mathrm{S}$ & A & $\mathrm{S}$ & $\mathrm{S}$ & I & I & A & A & A & A & A & $\mathrm{S}$ \\
\hline $\begin{array}{l}\text { Compatibilidade } \\
\text { com laranjeiras }\end{array}$ & $S$ & A & $\mathrm{A}$ & A & $S$ & I & $\mathrm{I}^{\mathrm{b}}$ & A & A & A & $\mathrm{S}$ & I \\
\hline
\end{tabular}

Onde: I = Insatisfatório; S = Satisfatório; A = Aceitável; DI = Dado Inexistente

${ }^{\mathrm{a}} \mathrm{M}=$ Solo com profundidade Média; $\mathrm{P}=$ Profunda e $\mathrm{R}=$ Raso .

b Veja Tabela 3

Fonte: Adaptado de CARLOS et al., 1997

do pelas suas raízes, os porta-enxertos estão constantemente expostos à infecção por Phytophthora sp. Além de raízes necrosadas, os sintomas são evidentes na região do colo das plantas. A copa também pode influenciar a tolerância do porta-enxerto à doença, sendo que os clones nucelares, por serem mais vigorosos que os clones velhos, conferem maior suscetibilidade ao porta-enxerto. Contrariando as linhas de pensamento anteriores que relacionavam a gomose de Phytophthora sp. a plantas debilitadas esta parece estar relacionada a sua atividade fisiológica. Esta maior suscetibilidade de plantas com vigoroso desenvolvimento e com grande número de brotações novas pode ser atribuída à maior atividade do floema nestas combinações cítricas, já que os fungos colonizam estes tecidos (FEICHTENBERGER, 1990; CARLOS et al. 1997).

Com relação aos mecanismos de resistência de algumas cultivares recomendadas de portaenxertos, AFEK \& SZTEJNBERG apud KOLLER (1994) relataram que as plantas reagem às infecções microbianas produzindo fitoalexinas. Nos citros a sesalina é sintetizada pelas raízes e o escarpone $(6,7$ Dimetoxicumarina) é sintetizado na casca das árvores em decorrência de infecções com Phytophthora. Os referidos pesquisadores verificaram que as plantas resistentes sintetizam maior quantidade de escarpone do que as suscetíveis. Por outro lado, o limoeiro 'Rugoso' revela-se suscetível à $\boldsymbol{P}$. citrophthora na temperatura inferior a $20{ }^{\circ} \mathrm{C}$ e torna-se resistente na temperatura de $28^{\circ} \mathrm{C}$. Esse fenômeno está relacionado à síntese de escarpone, que é maior em temperaturas elevadas.

Uma boa parte dos porta-enxertos utilizados comercialmente possuem diferentes graus de tolerância à Phytophthora sp. Os trifoliatas, a laranjeira azeda, e plantas de $\boldsymbol{C}$. macrophyla, possuem baixa suscetibilidade e os limoeiros verdadeiros, a laranjeira doce, a limeira ácida, o limoeiro rugoso e o pomeleiro possuem suscetibilidade alta a muito alta (FEICHTENBERGER, 1990).

\section{Tristeza dos Citros}

Das doenças associadas as plantas cítricas, a tristeza impõe-se como limitante a determinadas combinações de copa e porta-enxerto. O parque citrícola brasileiro quase foi totalmente destruído na década de 40 pelo uso de combinações de laranjeiras doce sobre azeda, esta última intolerante ao vírus da tristeza. A presença de estirpes virulentas e do mais eficiente vetor, o pulgão preto (Toxoptera citricidus), efetivamente colaboraram para isto (MOREIRA \& MOREIRA, 1991).

O uso de porta-enxertos tolerantes para cultivares de copas suscetíveis é condição à própria existência de pomares viáveis, especialmente em regiões onde a doença é endêmica e existam efici- 
entes vetores associados, como ocorre em todas as regiões do Brasil (CARLOS et al., 1997), portanto, verifica-se também para esta doença, a importância da copa na escolha do porta-enxerto em função de seu nível de tolerância à Tristeza.

O Trifoliata e alguns de seus híbridos são resistentes à infecção de Tristeza, ou seja, o vírus não se multiplica nestas plantas mesmo quando são enxertadas com borbulhas contaminadas. A maioria das tangerineiras, laranjeiras doces, e limoeiro cravo, geralmente não mostram os sintomas, apresentandose, portanto, como tolerantes.

\section{Declínio dos citros}

Com agente causal ainda desconhecido, este problema está presente em vários países. No Brasil, a ocorrência é generalizada nos estados produtores. As perdas no Estado de São Paulo chegaram a 10 milhões de árvores por ano, sendo este fato considerado como um dos problemas que mais causa danos aos pomares paulistas (CARLOS et al., 1997).

As hipóteses que sustentavam uma origem abiótica para a anomalia, como desordem nutricional ou estresse fisiológico, não puderam ser mantidas após a transmissão desta por enxertia de raízes. Para vários autores, deve existir algum patógeno relacionado ao sistema radicular dos porta-enxertos, uma vez que a anomalia não se transmite por enxertia de ramos (CARLOS et al., 1997).

Tendo em vista que o declínio tem sido diagnosticado em plantas cítricas enxertadas sobre limoeiros 'Cravo' e 'Volkameriano', Poncirus trifoliata e alguns de seus híbridos, pode-se concluir que o único meio de controle que pode ser recomendado para essa moléstia é o uso de portaenxertos tolerantes (KOLLER, 1994).

A escolha dos porta-enxertos em função do nível de tolerância à anomalia é bastante importante na maioria das regiões citrícolas brasileiras. Onde a anomalia ocorre intensamente, as chances de se ter um pomar viável sobre limoeiro 'Cravo' ou Trifoliata, por mais de 12 ou 15 anos, são relativamente baixas. Utilizando outros porta-enxertos com maior tolerância, permite-se ao produtor obter retorno econômico por um período de tempo maior, que geralmente pode chegar a 25 ou 30 anos (CARLOS et al., 1997). Na tabela 2 está descrito os principais porta-enxertos e suas características perante ao declínio dos citros.

\section{Influência dos porta-enxertos na resistência à seca}

Esta característica é bastante importante em regiões com distribuição irregular de chuvas, como é o caso da citricultura paulista. A característica de resistência a seca, dos principais portaenxertos, pode ser observado na tabela 2 .

Embora a translocação de água não seja diretamente correlacionada com a quantidade de raízes, verifica-se que as diferenças entre os portaenxertos podem ser atribuídas à distribuição de raízes fibrosas e à eficiência do sistema de transporte da mesma (CARLOS et al., 1997; DONADIO et al., 1993). A característica profundidade do sistema radicular e a baixa transpiração em certas combinações copa $\mathrm{x}$ porta-enxertos tem sido associadas à maior capacidade de resistir a deficiências hídricas (CUNHA \& SOARES FILHO, 1988).

O citros, sob um déficit hídrico, entram em uma intensa transpiração, aumentando a condutividade estomática e diminuindo o potencial de água foliar, isso pode levar a um incremento na síntese de etileno, determinando uma queda de folhas, ocorrendo assim uma redução na superfície de perda de água, aumentando o potencial hídrico das folhas remanescentes (CASTRO, 1994). No planalto paulista, após períodos de estiagens, pode-se verificar que os limoeiros 'Cravo' e 'Volkameriano' apresentaram um desempenho satisfatório nestas condições. A tangerineira 'Cleópatra' e o citrumeleiro 'Swingle', geralmente, induzem uma massiva queda de folhas durante estiagens prolongadas, embora as plantas se recuperem muito bem durante a primavera e o verão seguintes. A tangerineira 'Sunki', as laranjeiras doces, o Trifoliata, os citrangeiros e o tangeleiro 'Orlando' têm-se mostrado pouco tolerantes nestas condições (CARLOS et al., 1997).

\section{Compatibilidade entre porta-enxerto e copa}

O processo de enxertia, geralmente, une dois materiais vegetais geneticamente distintos que passam a compartilhar uma série de fatores essenciais à sobrevivência de ambos. Este relacionamento é considerado como simbiótico, mutuamente benéfico, embora os interesses e necessidades da copa e do porta-enxerto sempre sejam comuns. O ganho esperado no desempenho da copa está em função da eficiência do porta-enxerto utilizado e da afinidade dos tecidos de ambos. Esta compatibilidade é fundamental para o sucesso de um pomar comercial ao longo do tempo. Associa-se a compatibilidade entre copas e porta-enxertos à uniformidade nos diâmetros dos troncos próximos à linha de enxertia. Entretanto, os troncos dos porta-enxertos como o trifoliata e seus híbridos, que geralmente apresentam um diâmetro maior que os de suas copas, são compatíveis com um grande número de espécies cítricas (CARLOS et al. 1997). 
Combinações incompatíveis apresentam na região de enxertia, externamente, uma linha de depressão na casca acompanhada por uma brotação anormal do porta-enxerto. Internamente, ocorre uma linha de goma de coloração marrom (MÜLLER $\boldsymbol{e t}$ al., 1996; CARLOS et al. 1997).

As incompatibilidades mais comuns estão listadas na tabela 3. As verdadeiras incompatibilidades são raras e causadas pela translocação de compostos e ocorrem usualmente entre Citrus sp. e gêneros afins e não devem se confundidas com doenças.

\section{Principais porta-enxertos utilizados e suas características}

Os efeitos dos principais porta-enxertos comerciais de citros utilizados no mundo, foram relatados por uma série de pesquisadores. A tabela 2 lista os principais porta-enxertos e suas características.

A tabela 2 relaciona, de forma direta, a cada porta-enxerto, os tópicos abordados anteriormente. Cabe ressaltar, novamente, alguns fatores limitante, como: Laranjeira azeda e sua incompatibilidade com laranjeiras, problemas de declínio dos citros no principal porta-enxerto utilizado no Brasil (Limoeiro 'Cravo'), entre outros.

$\mathrm{Na}$ tabela 4 listam-se algumas características de interesse dos viveiristas, principalmente quanto à época de maturação dos frutos, que pode variar com o clima, antecipando-se nas regiões quentes e atrasandose nas frias. Observa-se que o período central de maturação vai de maio a julho e que conforme o tamanho dos frutos há um maior ou menor número de frutos por caixa de $25 \mathrm{~kg}$. Um dado importante é quanto ao número de sementes por fruto, que no caso dos portaenxertos listados, pode variar de 3 (Tangerineira 'Sunki') até 38 (Trifoliata). Um maior número de sementes de um porta-enxerto pode ser um fator determinante da preferência do viveirista.

Nota-se que dificilmente encontraremos um porta-enxertos que atenderá a todas as limitações da cultura, entretanto devemos buscá-lo de forma a atender as principais limitações da propriedade e juntamente com isto, diversificar o seu uso na propriedade. KOLLER (1994) cita que é aconselhável a utilização de três ou mais porta-enxertos, sendo que $50 \%$ da área do pomar poderia ser plantada com o porta-enxertos de melhor rendimento e os $50 \%$ da área restante podem ser divididos em talhões usando outros dois ou três portaenxertos também de boas performance.

\section{Melhoramento genético para a obtenção de porta- enxertos}

Até a metade do século XIX predominou a propagação por sementes, quando problemas com
Tabela 3 - Incompatibilidades mais comuns entre combinações cítricas.

\begin{tabular}{ll}
\hline \multicolumn{1}{c}{ Copa } & \multicolumn{1}{c}{ Porta-enxerto } \\
& \\
& \\
& Trifoliata \\
& Citrumelo Swingle 4475 \\
& Limão Rugoso da Flórida \\
Laranjeira 'Pêra' & Limão Volkameriano \\
& Citrumelo Swingle 4475 \\
& Trifoliata \\
Laranjeira 'Shamouti' & Limão Rugoso da Flórida \\
Seleta de Itaboraí & Trifoliata \\
& Citranges Troyer e Carrizo \\
Limoeiro 'Eureka' & Trifoliata \\
& Citranges \\
Limoeiro 'Siciliano' & Citrumelo 4475 \\
& Trifoliata e seus híbridos \\
Tangor 'Murcott' & Trifoliata e seus híbridos \\
Calamondins & Citrange Troyer \\
Tangerineiras 'Satsuma' & Trifoliata \\
Cidra & \\
&
\end{tabular}

Fonte: CARLOS et al., 1997.

Phytophtora sp., determinaram o uso de portaenxertos tolerantes. No Brasil, no início deste século, utilizava-se a laranjeira doce como principal porta-enxerto que, por suscetibilidade à seca e gomose, levou ao uso da laranja azeda. A intolerância deste porta-enxerto ao vírus da tristeza praticamente dizimou a citricultura brasileira na década de 40. Após a década de 60, o limoeiro 'Cravo' passou a liderar a preferência dos citricultores em alguns anos atingindo $99 \%$ das mudas produzidas. Apesar deste ter boas características e ter impulsionado a citricultura paulista, a partir da década de 70, com o surgimento do 'declínio dos citros', optou-se pelo uso de outros porta-enxertos. Entre 1984 e 88, a tangerineira 'Cleópatra' teve seu uso aumentado (24\% das mudas produzidas) e em escala menor, outros portaenxertos como a tangerineira 'Sunki', o limoeiro 'Volkameriano', Trifoliata e seus híbridos (CARLOS, 1997). No Rio Grande do Sul o Poncirus trifoliata é o porta-enxertos mais utilizado, alcançando até $97,53 \%$ das mudas produzidas em 1998 (SCHÄFER, 2000).

Portanto, com o constante surgimento de novas doenças, fatores climáticos e práticas culturais cria-se uma demanda para novos porta-enxertos de citros. Apesar da ampla diversidade genética apresentada pelos citros em geral, poucos genótipos possuem características hortícolas aceitáveis para uso direto como porta-enxertos (SWINGLE \& REECE, 1967). 
Tabela 4 - Época de maturação, número de frutos por caixa e número de sementes por fruto de diversos porta-enxertos de citros no Rio Grande do Sul.

Porta-enxertos

Época de maturação Número de frutos/caixa* Número de sementes/fruto

\begin{tabular}{lccc}
\hline & & & \\
Limoeiro 'Cravo' & Mai-Ago & 582 & 15 \\
Limoeiro 'Volkameriano' & Mai-Jul & 153 & 10 \\
Limoeiro 'Rugoso' & Mai-Jul & 147 & 15 \\
Trifoliata & Mar-Mai & 551 & 38 \\
Tangerineira 'Sunki' & Jul-Ago & 2757 & 3 \\
Tangerineira 'Cleópatra' & Ago-Set & 1164 & 14 \\
Citrangeiro 'Troyer' & Mai-Jul & 337 & 15 \\
Laranjeira Azeda & Jun-Ago & 123 & 25 \\
Laranjeira Doce & Jun-Ago & 337 & 13 \\
Tangeleiro 'Orlando' & Jun-Ago & 233 & 18 \\
Citrumeleiro ' Swingle' & Mar-Jul & 245 & 15 \\
& & & \\
\hline
\end{tabular}

* Caixa de 25 kg - Fonte: KOLLER, 1994 \& CARLOS et al., 1997.

A facilidade com que ocorrem cruzamentos entre as espécies do gênero Citrus e até entre outros gêneros como o Poncirus e Fortunella $e$ a produção de híbridos férteis têm se tornado uma ferramenta para muitos melhoristas que, desde o final do século passado, buscam combinar características de interesse ao melhoramento presentes nas espécies e gêneros para atender à demanda de novas variedades de porta-enxertos.

Já na França, em 1894, foram obtidos alguns híbridos (citranges) através da hibridização de Citrus sinensis com Poncirus que apresentam maior resistência ao frio do que as laranjeiras (RAMOS, 1990). No mesmo ano, na Flórida, Swingle e Webber buscando encontrar híbridos resistentes ao frio, produziram alguns tangelos $(\boldsymbol{C}$. reticulata $\times$ C. paradisi) e citranges (WEBBER \& SWINGLE, 1905 citado por MOREIRA \& PIO, 1991), sendo que alguns destes híbridos apresentam interesse como porta-enxertos (MOREIRA \& PIO, 1991).

No Brasil, por volta de 1935 , foram realizados os primeiros trabalhos de melhoramento em citros com testes comparativos entre diferentes porta-enxertos e produção de clones nucelares, na Estação Experimental do Instituto Agronômico de Campinas em Limeira/SP (RAMOS 1990). No Rio Grande do Sul, na Estação Experimental de Taquari, foram obtidos Citranges por hibridações, identificados como C-8, C-12, C13, etc. (SOUZA et al., 1992).

Porta-enxertos comerciais de citros normalmente não satisfazem todos os critérios de seleção para um local específico, isto é, resistência a doenças e nematóides, resistência ao frio, adaptação a vários tipos de solo, tamanho apropriado de planta e alto rendimento e qualidade de fruto (CASTLE $\boldsymbol{e t}$ al. 1987, citado por GROSSER et al., 1994). Desta forma, o melhoramento genético para novas variedades de portaenxertos, busca nos cruzamentos intra e interespecíficos uma maior variabilidade genética. De uma maneira geral, o melhoramento de variedades de porta-enxertos é direcionado no sentido de resistências a doenças como a tristeza, gomose e declínio; resistência a pragas como as brocas, cochonilhas e nematóides; melhoria na relação copa/porta-enxerto; redução do tamanho da copa sem afetar a produtividade e qualidade do fruto; tolerância a déficit hídrico e maior adaptabilidade a fatores nutricionais (GROSSER \& GMITTER JR., 1990).

No Brasil, pode-se considerar a obtenção de novas variedades copa e porta-enxerto como um objetivo importante no melhoramento genético, principalmente em se tratando de material resistente a doenças (CUNHA SOARES FILHO, 1988). Apesar das hibridações terem sido amplamente utilizadas no melhoramento genético de porta-enxertos em citros, a sua utilização tem sido limitada por fatores biológicos da cultura como: poliembrionia, heterozigozidade, esterilidade masculina, incompatibilidade e grande período juvenil (CAMERON \& FROST, 1968). Recentemente a produção de híbridos somáticos tetraplóides que combina genótipos diplóides via fusão de protoplastos tem sido uma estratégia importante na obtenção de novas variedades de portaenxerto de citros com características hortícolas desejáveis (GROSSER $\boldsymbol{e t}$. al., 1992; 1994, LOUZADA et al., 1992; 1993; 1994, GROSSER et. al., 1998). Uma importante característica apresentada pela fusão de protoplastos como uma forma de melhoramento genético é a possibilidade de combinar Citrus com gêneros relacionados que possuam características importantes, principalmente quando não são possíveis os cruzamentos intergenéricos por hibridação natural.

\section{CONSIDERAÇÕES FINAIS}

O uso e a diversificação de porta-enxertos é uma importante ferramenta para melhorar a qualidade da citricultura, devendo essa atender às expec- 
tativas do produtor, propriedade e do mercado consumidor.

Nem todos os aspectos relacionados à interação copa - porta-enxerto estão suficientemente esclarecidos.

A pouca diversificação de porta-enxertos e a inexistência de produção de mudas certificadas no Rio Grande do Sul, aliadas à dispersão de doenças, põem em risco a atual citricultura. Isto leva à preocupação com o melhoramento genético que poderá contribuir para a seleção de materiais adaptados e com tolerância, principalmente, a doenças.

\section{REFERÊNCIAS BIBLIOGRÁFICAS}

ALBRIGO, G. Influências ambientais no desenvolvimento dos frutos cítricos. In: SEMINÁRIO INTERNACIONAL DE CITROS - FISIOLOGIA, 2., 1992, Bebedouro-SP. Anais.. Campinas, SP : Fundação Cargill, 1992. 226p. p.100 - 106.

ALVARENGA, L.R., BENDEZU, J.M., TEIXEIRA, S.L., $\boldsymbol{e}$ t al. Comportamento da laranjeira 'Valência' (Citrus Sinensis (L.) Osb.) sobre 12 porta-enxertos em Porteirinha - MG. In: CONGRESSO BRASILEIRO DE FRUTICULTURA, 8 , 1986, Brasília. Anais... Brasília:SBF, 1986. v.1, 268p., p.153-159.

CAMERON, J.W., FROST, H.B. Genetics, breeding and nucellar embryony. In: REUTHER,W., BATCHELOR, L.D., WEBBER, H.J. (eds). The citrus industry. VI. Berkeley : University of California, 1968. V.2, p.325-370.

CARLOS, E.F., STUCHI, E.S., DONADIO, L.C. Portaenxertos para a citricultura paulista Jaboticabal : Funep, 1997. 47p. (Boletim citrícola n. 1)

CASTLE, W.S. Rootstock as a fruit quality factor in citrus and decidous tree crops. New Zealand Journal of Crop and Horticultural Science, New Zealand, v.23, p.383-394. 1995.

CASTLE, W.S., TUCKER, D.P.H., KREZDORN, A.H., et al. Rootstocks. Gainesville : University of Florida. Disponível on line em: http: Iwww.hammock.ifas.ufl.edu. 1992

CASTRO, P.R.C. Comportamento dos citros sob déficit hídrico. Laranja, Corderópolis, v.15, n.2, p.139-154, 1994.

CUNHA, M.A.P. DA, SORES FILHO, W. DOS S. Melhoramento genético dos citros: Novas variedades copa e portaenxerto. Revista Brasileira de Fruticultura. Cruz das Almas, v.10, n.3, p.63-70. 1988

DI GIORGI, F., IDE, B. Y., DIB, K., et al. Qualidade da laranja para industrialização. Laranja, Corderópolis, v.14, n.1, p.:97-118, 1993

DONADIO, L. C., CABRITA, J.R.M., SEMPIONATO, O.R., $\boldsymbol{e}$ al. Tangerineira Cleópatra: vantagens e desvantagens como porta-enxerto na citricultura. Laranja, Corderópolis, v.14, n.2, p.565-579, 1993

DORNELLES, C.M.M. Citricultura do Rio Grande do Sul. In: RODRIGUES, o, VIÉGAS, F., POMPEU JÚNIOR, J., et al. Citricultura brasileira. Campinas, SP : Fundação Cargill, 1991. v.1. p.1-29.
FAO. Oranges. Tangerines, mandarins, clementines and satsumas. Lemons and limes. Grapefruit and pomelos. Production yearbook. Roma, v.52, p.157-160. 1998.

FAO. Oranges. Tangerines, mandarins, clementines and satsumas. Lemons and limes. Grapefruit and pomelos. Production yearbook. Roma, v.50, p.157-160. 1996.

FEICHTENBERGER, E. Gomose de Phytophtora dos citros. Laranja, Corderópolis, v.11, n.1, p.97-122, 1990.

FIGUEIREDO, J.O., POMPEU JÚNIOR, J., RODRIGUEZ, O. et al. Competição de dez porta-enxertos para a laranjeira barão (Citrus sinensis [L.] Osbeck). In: CONGRESSO BRASILEIRO DE FRUTICULTURA, 1981, Recife. Anais.. Recife : Sociedade Brasileira de Fruticultura, 1981. v.2, 810p. p.501-516

FIGUEIREDO, J.O.; HIROCE, R. Influência do porta-enxerto na qualidade do fruto e aspectos nutricionais relacionados à qualidade. In: SEMINÁRIO INTERNACIONAL DE CITROS PORTA-ENXERTOS, 1, 1990, Jaboticabal. Anais... Jaboticabal : FUNEP, 1990. p.111-121.

FIGUEIREDO, J.O., POMPEU Jr. J., RODRIGUEZ, O., $\boldsymbol{e}$ t al. Competição de dez porta-enxertos para a mexeriqueira-do-rio (Citrus deliciosa Tenore). In: CONGRESSO BRASILEIRO DE FRUTICUlTURA, 5, 1979, Pelotas. Anais... Pelotas: Sociedade Brasileira de Fruticultura, 1979. 881p. p.442-453.

GROSSER, J. W., GMITTER Jr. F. G., LOUZADA, E. S. et al. Production of somatic hybrid and autotetraploide breeding parents for seedless citrus development. HortScience, Alexandria, v.27, n.10, p.1125-1127, 1992.

GROSSER, J. W., GMITTER Jr. F.G. Somatic hybridization of Citrus with wild relatives for germplasm enhancement and cultivar development. HortScience, Alexandria, v.25, n.2, p.147-151, 1990 .

GROSSER, J.W., JIANG, J., MOURÃO FILHO, F.F.A., $\boldsymbol{e} \boldsymbol{t}$ al. Somatic hybridization, An integral component of citrus cultivar improvement: Scion Improvement. HortScience, Alexandria, v.33, n.6, p.1057-059, 1998

GROSSER, J.W., LOUZADA, E.S., GMITTER Jr. F.G., et al. Somatic hybridization of complementary citrus rootstocks: five new hybrids. HortScience, Alexandria, v.29, n.7, p.812$813,1994$.

HIROCE, R., POMPEU Jr., FIGUEIREDO, J.O. Efeito de dez porta-enxertos na composição mineral das folhas da laranjeira 'Valência'. In: CONGRESSO BRASILEIRO DE FRUTICULTURA, 6, 1981, Recife. Anais... Recife: EMBRAPA-DDT/CNPq, 1981. v.2, 731p. p.626-633.

JOÃO, P.L. Situação e perspectiva da citricultura no Rio Grande do Sul. In: REUNIÃO TÉCNICA DE FRUTICULTURA, 5, 1998, Veranópolis. Anais... Veranópolis : FEPAGRO, 1998. 109p. p.15-18.

JOÃO, P.L., Procedimientos y problemática para la implantación de um programa de certificación de cítricos en el Estado de Rio Grande do Sul - Brasil. ValênciaEspanha : Universidade Politécnica de Valência - Instituto Valenciano de Investigaciones Agrarias, 1999. 97p.

KOLLER, O.C. Citricultura: laranja, limão e tangerina. Porto Alegre : Rigel, 1994. 446p 
LEDO, A.S., LEDO, F.J.S., RITZINGER, R., et al. Portaenxertos para laranjeiras-doces (Citrus sinensis (L.) Osb.) em Rio Branco, Acre. Pesquisa Agropecuária Brasileira. Brasília, v.34, n.10, p.1211-1216, 1999.

LIMA, J.E.O. de. Novas técnicas de produção de mudas cítricas. Laranja, Corderópolis, v.7, n.2, p.463-468, 1986.

LOUZADA, E.S., GROSSER, J. W. GMITTER Jr. F.G. Intergeneric somatic hybridization of sexually incompatible parents: Citrus sinensis and Atalantia ceylanica. Plant Cell Reports, Flórida, v.12, p. 687-690, 1993.

LOUZADA, E.S., GROSSER, J.W. Somatic hybridization of Citrus with sexually incompatible wild relatives. Biotechnology in Agriculture and Forestry, Berlin, v.27, p.427-438, 1994

LOUZADA, E.S., GROSSER, J.W., GMITTER Jr. F.G., et al. Eight new somatic hybrid citrus rootstocks with potential for improved disease resistance. HortScience, Alexandria, v.27, n.9, p.1033-1036, 1992.

MORAES, L.A.H., SOUZA, E.L. de S., BRAUN, J., et al. Cadeia produtiva da laranja no Rio Grande do Sul. Porto Alegre : Secretaria da Ciência e Tecnologia - Fundação Estadual de Pesquisa Agropecuária, 1998. 49p. (Boletim Técnico, 5).

MOREIRA, C.S. O sistema radicular das plantas cítricas. In: SEMINÁRIO INTERNACIONAL DE CITROS FISIOLOGIA, 2, 1992, Bebedouro-SP. Anais... Campinas, SP : Fundação Cargill, 1992. 226p. p.182-186.

MOREIRA, C.S., PIO, R.M.. Melhoramento de citros. In: RODRIGUEZ, O, VIEGAS, F., POMPEU Jr. J., et al. Citricultura brasileira. Campinas : Fundação Cargill, 1991. v.1, p.116-152

MOREIRA, C.S. MOREIRA, S. História da citricultura no Brasil. In: RODRIGUEZ, O., VIEGAS, F.C.P., POMPEU JÚNIOR, J., et al. Citricultura brasileira. 2.ed. Campinas: Fundação Cargill, 1991. v.1, p.1-21.

MÜLLER, G. W., TEÓFILO SOBRINHO, J., DOMINGUES, E T. Compatibilidade da laranjeira Pêra clone Bianchi, sobre doze porta-enxertos, após 23 anos de plantio. Laranja, Corderópolis, v.17, n.1, p.123-141, 1996.

POMPEU JÚNIOR, J. Porta-enxertos. In: RODRIGUEZ, O. VIEGAS, F.C.P., POMPEU JÚNIOR, J., et al. Citricultura brasileira. 2. ed. Campinas : Fundação Cargill, 1991. v.1, p. $265-280$

PORTO, O.M., MORAES, L.A.H., BRAUN, J. Porta-enxertos para limoeiro 'Siciliano'(Citrus limon Burmann) no Rio Grande do Sul. Revista Brasileira de Fruticultura, Cruz das Almas, v.14, n.3, p.119-124. 1992.
RAMOS D.J. Taxa de poliembrionia e identificação do embrião sexual "in vitro" dos porta enxertos Citrus limonia Osbeck cv. Cravo e Poncirus trifoliata (L.) Raf. Lavras. 1990. 73p. Dissertação (Mestrado em Agronomia) - ESAL, 1990.

RAMOS, J.D., PASQUAL, M., RIBEIRO, V.G., et al. Obtenção de porta-enxertos intergenéricos em citros. Pesquisa Agropecuária Brasileira. Brasília, v.32, n.10, p.1047-1051, 1997.

ROBERTO, S.R., LIMA, J.E.O., CARLOS, E.F. Produtividade inicial da laranjeira 'Valência' (Citrus sinensis L. Osbeck.) sobre oito porta-enxertos no Estado de São Paulo. Revista Brasileira de Fruticultura, Jaboticabal, v.21, n.2, p.119-122. 1999.

SCHÄFER G., DORNELLES, A.L.C. Produção de mudas cítricas no Rio Grande do Sul. - Diagnóstico da região produtora. Ciência Rural, Santa Maria, v.30, n.4, p.587-592, 2000

SOUZA, E.L.S., PORTO, O.M., RECK, S.R., et al. Comportamento do Tangor 'Murcote' em 12 porta-enxertos no Rio Grande do Sul. Revista Brasileira de Fruticultura, Cruz das Almas, v.14, n.3, p.105-112. 1992.

STUCHI, E.S., SEMPIONATO, O.R. SILVA, J.A.A. da. Influência dos porta-enxertos na qualidade dos frutos cítricos. Laranja, Corderópolis, v.17, n. 1, p. 159-178, 1996.

SWINGLE, W. T., REECE, P.C. The botany of citrus and its wild relativies. In REUTHER,W., BATCHELOR, L.D., WEBBER, H.J. (eds). The citrus industry. VI. Berkeley: University of California, 1967. p.190-430.

TEÓFILO SOBRINHO, J., POMPEU JÚNIOR, J. FIGUEIREDO, J.O., et al. Influência de onze porta-enxertos na produção e qualidade dos frutos da laranjeira 'Pêra', clone Bianchi. Laranja, Corderópolis, v.20, n.1, p.153-166, 1999.

VANNIERE, J., MARCHAL, J. Rootstock on nutrition trials on clementina in Corsica. III- The effect of mineral nutrition on the mineral composition of leaves of clementina SRA 63. Fruits, Paris, v.47, n.1, p.45-49, 1992

VITTI, G.C. Nutrição e crescimento de plantas cítricas. In: SEMINÁRIO INTERNACIONAL DE CITROS FISIOLOGIA, 2, 1992, Bebedouro-SP. Anais... Campinas, SP : Fundação Cargill, 1992. 226p. p.132-162.

WUTSCHER, H. K. Rootstoks effects on fruit quality. In FERGUSON, J.J., WARDOWSKI, W. F. Factors affecting fruit quality. Lake Alfred : University of Florida, 1988. p.24-34.

ZHUANG, Y.M., WANG, R.J., XIE, ZN, et al Effects of rootstock on the growth, fruiting and leaf mineral content of Ponkan mandarin. Acta Horticulturae, Wageningen, n.20, p.209-215, 1993.

Ciência Rural, v. 31, n. 4, 2001. 